\title{
What forest is in the light of people's perceptions and values: socio-cultural forest monitoring in Switzerland
}

\author{
Jacqueline Frick ${ }^{1}$, Nicole Bauer ${ }^{2}$, Eike von Lindern ${ }^{3}$, and Marcel Hunziker ${ }^{2}$ \\ ${ }^{1}$ Zurich University of Applied Sciences, Wädenswil, 8820, Switzerland \\ ${ }^{2}$ Swiss Federal Research Institute WSL, Birmensdorf, 8903, Switzerland \\ ${ }^{3}$ Dialog N - Research and Communication for People, Environment and Nature, Uster, 8610, Switzerland \\ Correspondence: Jacqueline Frick (envir.psy@gmail.com)
}

Received: 31 March 2017 - Revised: 14 March 2018 - Accepted: 21 March 2018 - Published: 19 November 2018

\begin{abstract}
Forest is an important element of Swiss landscape, with about $30 \%$ of the country covered by it, forming a finely structured patchwork together with water bodies, agricultural land and settlements. It is highly valued by residents as part of their everyday living and recreational environment. The aim of this paper is to provide knowledge about how residents perceive and value forests and what their dominant preferences are. The data were collected through the Socio-cultural Forest Monitoring (WaMos). In this survey, 3022 persons responded by telephone interview or online survey. Respondents were well informed about forest issues, especially about recreation, animals and protection from natural hazards. Nevertheless, functions such as wood production, air quality and biodiversity were rated as even more important than recreational functions. Mixed forests and multisensory experiences were preferred, whereas wilderness was only moderately approved of. Respondents did not much appreciate sports and fun infrastructure, but valued infrastructure for contemplative and social activities and for education about forest issues.
\end{abstract}

\section{Introduction}

Forests are highly important for residents of an area, region or country. They not only contribute substantially to the atmosphere of a landscape but also provide various benefits for people, both directly and indirectly. They represent attractive natural places to linger, play, do sports, observe and socialize. They provide demanded products such as wood, wild game, berries and mushrooms. They clean air and water and protect areas from avalanches, landslides and erosion.

Particularly in a densely populated area such as Switzerland, forest is a central part of almost all residents' everyday landscape. About $30 \%$ of the country is covered by forest, which forms a fine patchwork together with rivers, streams and lakes, agricultural land and settlements. Accordingly, there is a high competition of interests regarding forests. Forest policy is oriented largely on multifunctional forests. For policy and planning to maintain and improve the quality of this important part of the everyday landscape, it is therefore important not only to base management and development of forests towards ecological or productive aspects of the forest but also to have some evidence about the knowledge, attitudes and demands of residents about the forest. It should be known how forest is perceived both in terms of what it means for the population and what demands the population have with regard to the forest. To put it generally, in addition to objective approaches to definitions and value of forest (see Côte et al., 2018), information is needed about how forest is perceived by residents (i.e. what forest $i s$ for them) and what preferences they express regarding forest (i.e. what forest should be for them).

These questions are not only worth investigating to support current policy but are also worth monitoring over time, because the pressure on forests is increasing, in particular in densely settled areas, and these perceptions of the residents can therefore change. For example, the public discourse about forest dieback (waldsterben) in the 1980s and 1990s significantly influenced forest perceptions, and topics such as acid rain or the bark beetle continued to exist as significant forest problems in people's minds for a long time (e.g. Broggi, 2002). Furthermore, single events such as storms and natural disasters can significantly alter residents' 
perceptions in relatively short periods of time (see Wild-Eck et al., 2004). Finally, national and regional information and communication policy can be evaluated by regularly monitoring resident perceptions.

A nationwide survey about many different forest issues was conducted in Switzerland. The survey was part of the national Socio-cultural Forest Monitoring (WaMos) and represented the second wave of this monitoring. For WaMos 2 (Hunziker et al., 2012) the instrument was substantially enhanced, optimized and adapted to current conditions. The various topics of the survey were developed in an extensive process with national forest experts from science, administration and practice.

Three areas of the survey, and therefore three sets of questions from the available data, are of particular interest for studying the general perceptions people have regarding forests: (a) knowledge about forests, (b) preferences for certain forest types and features and (c) the attitudes people hold regarding the importance of different functions of forests. Knowledge yields evidence about rather direct perceptions about what forest is for people, while residents' preferences and attitudes regarding the functions of forests yield more evaluative evidence about what forests should be.

The main concepts studied in WaMos 2, including the concepts relevant for this paper, are shown in Fig. 1. The concepts highlighted in dark boxes, i.e. forest knowledge, forest preferences and valuation of forest functions, are those most relevant for the superordinate question about what forest most generally - means to the residents. The other concepts (light boxes) are more relevant for attitudes and behaviour with regard to specific forest functions or specific forest management aspects.

\subsection{Knowledge about forest in the population}

Knowledge is a precondition for developing realistic perceptions of forest state as well as attitudes regarding desired forest development and forest management. Sufficient and transparent information, and a trustworthy information source, has been found to be central for acceptance of conservation measures (Schenk et al., 2007; Pauli, 2000). The need for information about forests in Switzerland was found to be high in previous studies such as WaMos 1 (BUWAL, 1999), in particular the need for independent, first-hand information from authorities. Furthermore, specific forest issues such as forest health have been investigated. For example, forest condition is perceived to be deteriorating (BUWAL, 1999; Dobré et al., 2006). The latter authors assume that reports about the state of forests worldwide (e.g. in the Amazon area) are responsible for this view and influence the perceptions of deterioration. Not surprisingly, a majority of residents felt that more had to be done to save the forests (Kleinhückelkotten et al., 2009). It has been found that people ascribed pollution as the main contributor to the condition of the forest (BUWAL, 1999); however, after heat waves, forest fires were also mentioned as contributors to forest conditions (Dobré et al., 2006). As mentioned above, it is very likely that the perceptions of forest conditions and the deterioration of forest health in the 1990s and even later were significantly influenced by the discourse about forest dieback that started in the early 1980s.

When asked about the area covered by forest, people often overestimated the area, and the actual forest growth was underestimated, with more than half of the participants assuming a decrease (BUWAL, 1999; Hertig, 1979), which reflects an answer pattern that can also be observed in Germany and other European countries (Kleinhückelkotten et al., 2009; Rametsteiner et al., 2009). This falsely perceived decrease is attributed to road construction and settlement (Hertig, 1979).

\subsection{Perceptions and attitudes about forest functions}

People have varying degrees of knowledge and perceptions about the functions that forests provide. Forest functions can be conceptualized according to ecosystem services. The Swiss Federal Office of Environment uses this conceptualization for its indicator systems (see MCPFE, 2003), and accordingly forest functions were based on ecosystem services for this project: provisioning services such as wood production or biodiversity, regulating services such as air and water quality or protection from natural hazards, and cultural services such as aesthetics and recreation. Residents' knowledge about forest functions is dependent on ecological awareness with people with low environmental awareness regarding forest services as less important than do people with high awareness (Lin et al., 2008). People regarded ecological and protection functions (soil stability, protection from erosion, air and water quality, climate and biodiversity) to be the most important functions of forests and production functions to be the least important (Dobré et al., 2006; Kumar and Kant, 2007; Lin et al., 2008; Ramesteiner et al., 2009; Šišák, 2011). In Switzerland, contribution to air quality and other ecological functions, as well as recreation, were rated as most important (Hertig, 1979; BUWAL, 1999), whereas production functions were rated as much less important. Overall, in most studies, ecological functions seem to be most important, followed by the social functions (wellbeing, recreation) and then production functions (wood production, employment, tourism). Elderly people and people living in regions with much forest (Kumar and Kant, 2007) rated production functions as more important. The importance of functions corresponded to the reason respondents mentioned for protecting forests (Kumar and Kant, 2007). Dobré et al. (2006) found an additional function: the forest is perceived as an "elsewhere" place that is accessible to everyone but which becomes something rare in the light of commercialization of many resources. Most studies have collected spontaneous open answers to the question about the important forest functions, and hardly any studies have measured the perceived 
Preconditions

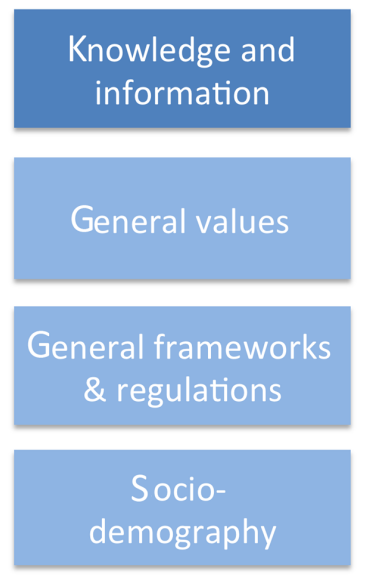

Human-forest relationship

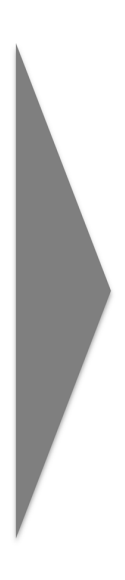

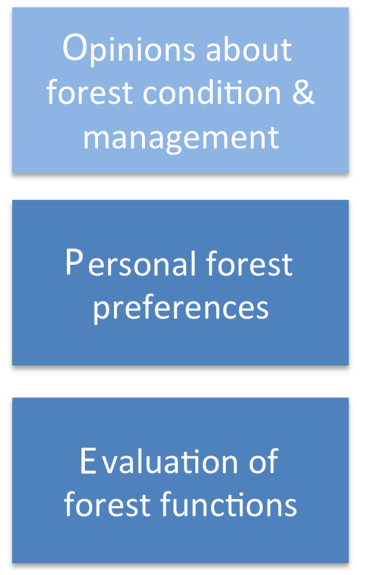

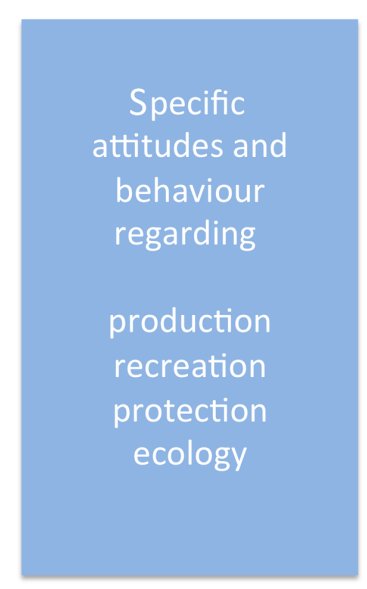

Figure 1. Relevant aspects and preconditions of the relationship which humans have with regard to the forest. All aspects studied in WaMos 2 are shown, and topics reported in this paper are highlighted (dark boxes).

values of several functions in the population at large (i.e. not just local stakeholders) and across larger regions with different forest types and uses. However, the evaluation of functions is crucial with regard to the demands of the population and questions of forest management.

\subsection{Forest preferences}

Preferences for landscape qualities have been researched for many years. In particular, the approaches of Kaplan and Kaplan as well as Purcell have been applied in numerous studies (e.g. Hunziker et al., 2008). Kaplan and Kaplan (1989) developed a preference model with four empirically derived factors: coherence, legibility, complexity and mystery. These factors can be "translated" into objective forest qualities (e.g. proportion of deadwood, structure, paths, forest edges). Furthermore, the familiarity with a scenery is important. Purcell's (1992) "typicality" approach assumes that humans build "default values" regarding the typical qualities of the environment. People have common default values, and a certain deviation from them is acceptable and raises interest, but larger deviations are perceived as negative. Overall, aesthetic qualities of forest preferences are difficult to define. People like complex and mysterious forests, coherence and legibility, familiarity and naturalness. Structures which are too "chaotic" are not preferred. Forests should provide variety of structures, height and forms and should also provide smooth transitions between them (Gobster, 1992; Hull et al., 2000).

Other studies were more specific and investigated natural qualities: broadleaf trees were preferred to conifers, although visitors appreciated mixed forest (e.g. Abildtrup et al., 2013). Preferences for forest maintenance have also been investigated. Earlier Swiss surveys (Hertig, 1979; BUWAL, 1999) indicated that the population mostly regards the forest area as sufficiently large, while to a minor portion of people it seems too small and only rarely is it regarded too large. About the same proportion of Swiss residents regard an increase of wilderness to be positive as the proportion who regard it as negative (Bauer et al., 2009). An overall positive attitude towards wilderness has been found in other studies (Kleinhückelkotten et al., 2009). In a study in France (Dobré et al., 2006), half of the participants rated deadwood as negative and saw it as a sign of poor maintenance of forests. However, these cultural values and preferences for maintenance change over time: in 1978, as much as $80 \%$ of French respondents preferred a manicured, park-like forest without wilderness (Hertig, 1979). Furthermore, these perceptions are fundamentally different in national parks, where $88 \%$ approve of leaving deadwood in the forest (Stelzig, 2000), even though half of the respondents reported that they felt sad about deadwood. Similarly, Hunziker (2000) found that deadwood in the Swiss National Park was perceived as aesthetically displeasing by $32 \%$ of the respondents, but less than $20 \%$ wished more maintenance. Fifteen years later, Backhaus et al. (2013) found that more than $90 \%$ of respondents rated the forest in the National Park as appealing and did not wish it to be more maintained. Furthermore, deadwood was only marginally associated with pollution or climate change. Similar perceptions, which were shaped during the 1980s in the course of the discussion about forest dieback, can be found with regard to the bark beetle (Müller et al., 2008). People get used to the sight of bark beetle damage. In particular, those with a high affinity to the park rated bark beetles more positively and considered them to be normal. 


\subsection{Research objectives and research questions}

The objective of this paper is to present general descriptive evidence about the Swiss population and to investigate the structure of perceptions regarding forest, rather than explaining these views by the various preconditions. For broad, nationwide communication, as well as for general forest management, the central tendencies within the population are relevant. Furthermore, we are interested in finding meaningful structures in these general perceptions. As we have pointed out, three areas are important to effectively study and monitor residents' general forest perceptions. Direct perceptive aspects (what forest is) can be covered by assessing knowledge, while evaluative or judgment-based aspects (what forest should be) can be evaluated by assessing preferences and opinions about forest functions.

The following research questions were therefore chosen to guide this research in order to pursue the general objective:

a. How much do respondents know about forest issues?

b. How important are different forest functions for respondents, and can functions be structured into key dimensions?

c. Which general, natural and man-made forest qualities do respondents appreciate, and can these preferences be structured into key dimensions?

\section{Methods}

The survey was conducted by telephone (CATI) between October and November 2010. Respondents were informed about the study by mail and consequently contacted by telephone. After a few introductory questions, respondents had the option to either finish the survey by telephone or complete the remaining questions in an online questionnaire. Of all respondents $59 \%$ answered by telephone and $41 \%$ by online survey.

To achieve a sample representative of the Swiss population, 9500 household addresses and telephone numbers were drawn by the Federal Office of Statistics using a random procedure. Within households, an adult person was chosen to be interviewed using a random procedure. A total of 3022 useable interviews or online surveys were completed $(32 \%$ of the drawn sample). If non-systematic dropout (e.g. business numbers, number out of order, target participant absent during survey phase, language problems) is not considered part of the net sample, the response rate was $38 \%$ of the net sample, and the remainder of the net sample either was not reached, did not answer or refused to participate. The interview/survey language was German in $67 \%$ of the cases, while $23 \%$ of the interviews were conducted in French and $10 \%$ in Italian.
The key characteristics of the sample corresponded closely with the actual Swiss population: $51.9 \%$ of respondents were female; the mean age was 52.5 years (slightly higher than the mean of all Swiss adults, which was 49 years), with the median at 52 years and the mode at 46 years. So the response rate was slightly biased towards older participants. Also, the usual educational bias could be observed, with $55 \%$ of respondents having vocational degrees, $9 \%$ having completed grammar school or seminars, $10 \%$ a higher education and $16 \%$ university education. The majority of respondents $(72 \%)$ lived in urban, suburban or peri-urban areas, while $7 \%$ lived in industrial-tertiary communities and $13 \%$ lived in rural or agrarian communities; $28 \%$ of respondents were members of an environmental association at the time of the survey.

The survey contained 87 questions and several subquestions, which were either newly developed or derived from WaMos 1, to assess the concepts (see Fig. 1). Questions were tested in four pre-tests with 150 persons and optimized for comprehensibility, appropriateness of answering options, length and language. The questions relevant for this paper are those regarding forest knowledge (nine questions), evaluation of forest functions (two questions) and preferences (four questions). The specific questions used are listed in the results section with sub-items listed in the result tables.

Data analysis (using the statistical package SPSS) was mainly based on comparison of frequencies of answers as well as means and standard deviations of responses. Furthermore, we applied principal component analysis with varimax rotation (orthogonal transformation). This procedure reduces complexity in data and explores dimensionality. It detects underlying constructs (e.g. forest preferences) based on the contributing variables (e.g. preference for sounds, natural elements). The result relates to a set of uncorrelated factors into which the variables are grouped, which can then be interpreted and named as underlying constructs. Factor loadings indicate the correlation between the single variables and the factors and, therefore, how much of the variable is explained by the factors.

\section{Results}

This paper focuses on those results from the whole survey that contribute to an understanding of people's general perception of forest. As we have pointed out, this perception has two main aspects: a more perceptive component about what forest is and a value- or judgment-based component about what forests should be. So firstly, the relevance of perceptive cognitions is discussed, in particular knowledge about different issues (see Sect. 3.1). In a second section (Sect. 3.2), evaluations of what is important (i.e. forest functions) are discussed; in a third section (Sect. 3.3), what is appreciated about forests, (i.e. forest preferences) is presented. 
Table 1. How respondents felt informed about forest issues and wished more information about them $(n=2951)$.

\begin{tabular}{lrr}
\hline Issue & $\begin{array}{r}\text { Percentage of subjectively } \\
\text { well-informed respondents }\end{array}$ & $\begin{array}{r}\text { Percentage of respondents } \\
\text { wishing for more information }\end{array}$ \\
\hline Forest in Switzerland in general & $70 \%$ & $85 \%$ \\
Recreational space for humans & $89 \%$ & $64 \%$ \\
Rules of conduct & $83 \%$ & $71 \%$ \\
Protection from natural hazards & $81 \%$ & $77 \%$ \\
Animals & $79 \%$ & $78 \%$ \\
Climate change & $74 \%$ & $84 \%$ \\
Conservation & $71 \%$ & $83 \%$ \\
Plants and trees & $71 \%$ & $79 \%$ \\
Forest health & $60 \%$ & $85 \%$ \\
Role for clean drinking water & $59 \%$ & $83 \%$ \\
Wood production & $53 \%$ & $71 \%$ \\
Land tenure & $47 \%$ & $64 \%$ \\
Forest conditions worldwide & $41 \%$ & $79 \%$ \\
\hline
\end{tabular}

\subsection{Subjective and objective knowledge about forests}

Knowledge can be assessed objectively by asking test questions or subjectively by asking respondents to rate how well informed they feel about a certain topic. We used both forms of knowledge assessment.

First of all, many Swiss residents seemed to have a strong tradition of visiting forests, with $87 \%$ of the sample reporting that the forest was rather important or very important for them in their childhood, while only $13 \%$ reported that forests were rather unimportant or absolutely unimportant in their childhood. Therefore it can be assumed that the respondents had some experience-based knowledge about forests and not only knowledge imparted through media.

Participants were then asked to rate how well they felt they had been informed about forests. In this general sense, $18 \%$ of the population felt very well informed, $62 \%$ felt well informed and $20 \%$ felt badly or very badly informed.

All participants, except those who reported that they felt very badly informed about forests, were then asked to rate how well they felt they had been informed about specific issues related to forests (see Table 1).

Respondents felt particularly well informed about issues related to recreation, followed by protection from natural hazards. Ecological issues such as conservation and climate change, as well as plants and animals, were also well known. However, people reported knowing less about forest health and the role forests play for clean water, wood production or land tenure.

Participants were then asked whether they wished to learn more about forest issues. The question was confirmed by $61 \%$ of respondents, while $39 \%$ declined. A follow-up question about which particular issues participants wished to gain more knowledge revealed that forest health and climate change were the most popular topics, followed by conservation and water. Respondents reported less interest in learn- ing more about recreational use, wood production and forest tenure.

Specific objective knowledge questions consisted of an estimate of the forest area and forest health, as well as their changes within the past 20 years. Participants were asked to estimate the proportional area of forest in Switzerland. With a mean estimate of $30.5 \%$ (median $30 \%$, mode $30 \%$ ) respondents were close to the actual forest area of $31 \%$. In the past 20 years, the forest area was estimated by $28 \%$ of residents to have increased (which is actually the case), while $36 \%$ assumed it to have remained constant and $37 \%$ assumed it to have decreased. With regard to forest health, $85 \%$ of the population regarded forest health as either good or very good, while $15 \%$ regarded it to be either bad or very bad. Asked about the change in forest health in the past 20 years (which has been stabilizing in some indicators, deteriorating in others), $24 \%$ of the respondents estimated it to have deteriorated, while $51 \%$ assumed it to have remained constant and $26 \%$ assumed it to have improved.

\subsection{Perceptions about forest functions}

With regard to more evaluative cognitions, i.e. how people think that a forest should be, we can build upon data from two sets of survey questions. The first set was about forest functions in which we asked participants to spontaneously name what came to their mind about "forest functions". It was added that they should indicate "what forest is useful and necessary for" and "what we need it for". Answers were categorized post hoc. Many respondents mentioned several functions. The most frequent mentions were categorized into a theme about air: provision of oxygen, fresh air or clean air. The second most frequent mentions were about production: wood, economic aspects, hunting or other forest use. The following categories related to habitats and natural hazards. Recreation was mentioned significantly less frequently, 
Table 2. Free associations with regard to "functions of the Swiss forest".

\begin{tabular}{lr}
\hline $\begin{array}{l}\text { Categorized free associations } \\
\text { (most frequent mentions) }\end{array}$ & $\begin{array}{r}\text { Percentage of } \\
\text { respondents* }\end{array}$ \\
\hline (Clean) Air, oxygen & $48 \%$ \\
Economy, production, use & $40 \%$ \\
Habitat, animals, plants, ecology & $38 \%$ \\
Protection from natural hazards & $37 \%$ \\
Recreation & $25 \%$ \\
Water quality, groundwater, drinking water & $8 \%$ \\
Climate, $\mathrm{CO}_{2}$, greenhouse effect & $7 \%$ \\
Aesthetics, landscape & $4 \%$ \\
\hline
\end{tabular}

* Total of 6439 associations mentioned by the 3022 respondents. Answers falling into categories not presented in this table were mentioned by less than $1 \%$ of respondents.

and climate- and water-related answers were even less frequently mentioned (see Table 2).

However, free associations cannot be interpreted directly as indicative of the perceived relevance of functions and merely indicate ideas that are most present or most easily retrievable for the respondents. They could be attributable to education, personal living situation, recent media coverage or many other sources. Therefore we asked participants to rate eight specific forest functions according to their importance for the Swiss population. Generally, all forest functions were rated between "important" or "absolutely important" (see Table 3). Providing clean air and water and protecting from natural hazards were each rated very high, while the participants rated the function of providing jobs and providing opportunities for recreation as the least important functions. Residents evidently also regarded functions as important when the functions did not have a direct benefit for the residents themselves. The importance ranking of forest functions did not correspond very strongly with the free associations described above. For example, "water quality", "home" and landscape or aesthetic functions were rarely mentioned, but when asked about them directly, people agreed with the importance of these functions. In contrast, economy and jobs were mentioned frequently but, when asked about it directly, their importance was ranked rather low.

Gender differences were found with regard to the evaluation of forest functions in the sense that women regarded all use-related functions to be significantly more important than men did. However, no gender differences were found regarding protective functions. Furthermore, a highly significant age effect was found, with all of the nominated functions being rated by older respondents as more important than the ratings given by younger respondents.

Principal components analysis was applied to determine whether importance ratings of forest functions could be collapsed into fewer dimensions. Two principal components resulted, which could be interpreted as "importance of use functions" (Cronbach's $\alpha=0.77$ ) and "importance of protective forest functions" (Cronbach's $\alpha=0.69$ ), which together explained $57 \%$ of the variance. Both factors were regarded as being very important by participants. The protective function had a mean importance rating of 3.87 $(\mathrm{SD}=0.35)$ and the use-related function a mean of 3.51 $(\mathrm{SD}=0.56)$, based on the average of the respective items.

\subsection{Forest preferences}

The second set of evaluative questions was about forest preferences. These were assessed with questions about the overall area, abstract landscape qualities (such as familiarity and variety) and specific natural and infrastructural elements.

Participants were asked to indicate whether they think that there is too much, enough or not enough forest in Switzerland: $5 \%$ of the population indicated that there is too much forest, $76 \%$ thought there is enough forest and $19 \%$ thought that there is not enough forest. Thus, the overall area covered by forest seemed to meet residents' preferences. More interesting with regard to the question what forest is for the people are their opinions about specific qualities. In response to the question "If you go to the forest, which of the following qualities appeal to you and which annoy you?" about a third of the respondents indicated that the qualities were "rather appealing", and about half of respondents rated them as "very appealing" (see Table 4).

Highly significant gender differences were found in all aspects: women reported all of the qualities to be more pleasing than men did. Furthermore, all aspects were rated significantly more pleasing with increasing age. In particular, the forest seemed to be more appreciated by residents over the age of 40 or 50 years.

A principal components analysis yielded two factors, which could be interpreted as landscape qualities that satisfy needs for "cognitive arousal" and "safety" (see Gehring, 2006). The first factor explained $48 \%$ and the second $16 \%$ of the variance.

The evaluation of several natural elements of forests proved to be more diversely rated than the general abstract qualities (Table 5). Participants were asked, "In the forest, different manifestations of nature are encountered. Which of them please you and which annoy you?" Some typical elements of forest nature such as sounds and smells, but also water and clearings, were very positively rated, while deadwood and dark, dense forests were less highly rated.

Gender differences were found in some of the elements: women found sounds and smells, mixed forests and clearings more appealing than men did, while men rated dark and dense forests more positively than women did. Also, the preference for multisensory forests and forest edges with shrubs increased significantly with increasing age.

These evaluations of natural forest elements were analysed using a principal components analysis. Three factors resulted that could be described as "multisensory forest", "wild for- 
Table 3. Importance of forest functions and factor loadings in principal component analysis (PCA).

\begin{tabular}{lrr}
\hline Items and factors & $\begin{array}{r}\text { Mean rating* } \\
(\text { SD })\end{array}$ & $\begin{array}{r}\text { Factor loading } \\
\text { in PCA }\end{array}$ \\
\hline Factor 1: importance of use-related forest functions & $3.33(0.67)$ & 0.81 \\
\hline The forest and forestry create jobs. & $3.53(0.59)$ & 0.77 \\
The forest produces wood. & $3.44(0.69)$ & 0.63 \\
The forest is a place for sport, recreation and leisure. & $3.56(0.67)$ & 0.61 \\
The forest is a part of "home". & $3.56(0.62)$ & 0.58 \\
The forest arranges and improves the landscape. & & 0.79 \\
\hline Factor 2: importance of protective forest functions & $3.81(0.41)$ & 0.76 \\
\hline The forest keeps the air clean and protects water quality. & $3.85(0.38)$ & 0.71 \\
The forest offers protection from natural hazards. & $3.87(0.35)$ & \\
The forest is a habitat for animals and plants. & \\
\hline * Anwering options from 0 ("absolutely unnecessary") to 4 ("absolutely necessary").
\end{tabular}

Table 4. Preferences for abstract landscape qualities, grouped into factors according to principal component analysis (PCA).

\begin{tabular}{|c|c|c|}
\hline $\begin{array}{l}\text { Landscape quality: } \\
\text { "If you go to the forest, what pleases and what annoys you?" }\end{array}$ & $\begin{array}{r}\text { Mean rating* (SD, } \\
\text { percentage "rather pleased" } \\
\text { or "very pleased") }\end{array}$ & $\begin{array}{r}\text { PCA factor } \\
\text { loadings }\end{array}$ \\
\hline \multicolumn{3}{|l|}{ Factor 1: cognitive arousal } \\
\hline It is pristine & $3.53(0.66,94 \%)$ & 0.81 \\
\hline It is versatile & $3.64(0.59,96 \%)$ & 0.81 \\
\hline There are fascinating things to discover & $3.50(0.69,93 \%)$ & 0.67 \\
\hline \multicolumn{3}{|l|}{ Factor 2: safety } \\
\hline I can find my way round & $3.20(0.87,82 \%)$ & 0.88 \\
\hline I feel safe & $3.37(0.79,88 \%)$ & 0.82 \\
\hline It is familiar & $3.45(0.69,92 \%)$ & 0.58 \\
\hline It is harmonious within itself & $3.42(0.74,89 \%)$ & 0.55 \\
\hline
\end{tabular}

* Answering options from 0 ("very annoying") to 4 ("very pleasing").

est" and "monoculture". Factor 1 contributed to $26 \%$, factor 2 to $14 \%$ and factor 3 to $13 \%$ of the variance.

Participants were asked the following: "There are many infrastructure elements in the forest. Which of them please you and which annoy you?" Despite the bias that was created with the question, a large part of the forest infrastructure was approved by the majority of respondents. In particular, forest roads and paths, benches, huts and shelters, fire sites, car parks, nature education trails, play areas and natural running tracks were popular (see Table 6). Mountain bike trails and rope tree climbing parks were annoying to the majority of respondents.

Highly significant gender differences were found for most of the infrastructure, with women rating them as being less annoying. Furthermore, older participants rated most sports infrastructure to be more annoying, but liked fire sites, education trails and car parks more than young participants did.
A principal components analysis was conducted for the items relating to attitudes towards infrastructure. Two factors could be interpreted as "sports infrastructure" and "infrastructure for social experiences". The first factor explained $36 \%$ and the second $12 \%$ of the variance.

\section{Discussion and conclusions}

The results from the WaMos 2 Swiss national survey on forest perceptions, attitudes and behaviour contribute to understanding what forest means for the Swiss population.

Firstly, the Swiss residents reported a strong connection with their forest, since the forest was important for a large majority in their childhood. Research question (a), about residents' knowledge, can be answered in the sense that residents felt well informed about forest issues and were interested to learn more, in particular about forest health, climaterelated issues and conservation. This high need for informa- 
Table 5. Preferences for natural forest elements, grouped into factors according to principal component analysis (PCA).

\begin{tabular}{|c|c|c|c|}
\hline Natural element in forests & Appealing $^{\mathrm{a}}$ & Annoying $^{\mathrm{a}}$ & PCA factor loadings \\
\hline \multicolumn{4}{|l|}{ Factor 1: multisensory forest } \\
\hline Natural sounds & $96 \%$ & $1 \%$ & 0.86 \\
\hline Smells of forest & $97 \%$ & $1 \%$ & 0.85 \\
\hline Mixed forest & $94 \%$ & $1 \%$ & 0.71 \\
\hline Streams, ponds & $88 \%$ & $4 \%$ & 0.56 \\
\hline \multicolumn{4}{|l|}{ Factor 2: wild forest } \\
\hline Deadwood & $39 \%$ & $48 \%$ & 0.78 \\
\hline Undergrowth & $51 \%$ & $34 \%$ & 0.75 \\
\hline Forest edge with shrubs & $60 \%$ & $18 \%$ & 0.62 \\
\hline Dense and dark & $41 \%$ & $40 \%$ & 0.59 \\
\hline \multicolumn{4}{|l|}{ Factor 3: monoculture } \\
\hline Almost only coniferous & $49 \%$ & $28 \%$ & 0.88 \\
\hline Almost only broadleaved trees & $56 \%$ & $22 \%$ & 0.83 \\
\hline \multicolumn{4}{|l|}{ Not contributing to any factor } \\
\hline Forest edge with large trees & $60 \%$ & $14 \%$ & $<0.50^{\mathrm{b}}$ \\
\hline Clearings & $76 \%$ & $13 \%$ & $<0.50^{\mathrm{b}}$ \\
\hline
\end{tabular}

tion corresponds with the earlier monitoring phase (BUWAL, 1999). Furthermore, residents had an adequate perception of the forest area and a slightly pessimistic perception about forest growth, which was also similar to the findings of earlier Swiss and European studies (BUWAL, 1999; Hertig, 1979, Kleinhückelkotten et al., 2009; Rametsteiner et al., 2009). The perceptions of forest health were also rather pessimistic, which is similar to earlier work (BUWAL, 1999; Dobré et al., 2006). As has been hypothesized by other authors, this view is most probably triggered by reports about worldwide forest conditions and still influenced by knowledge that was acquired during the period when forest dieback was prominent in the media. Based on the results about preferences, however, it can be concluded that more effort has to be made to spread knowledge about the importance of wilderness and deadwood for biodiversity in order to increase acceptance of such biodiversity measures.

Research question (b), concerning the value and structure of perceived importance of forest functions, was of a more evaluative nature. The functions that forests in Switzerland should mainly fulfil, according to the residents, were not primarily related to their own specific needs. Use-related functions, such as recreation, ranked much lower than the ratings for ecological and protective functions. People obviously regarded forests as primarily having intrinsic values and providing ecosystem services such as aesthetics and long-term regulating functions and were therefore willing to subordinate their own activities in the forest or forest products they benefit from on a short-term basis or in their everyday life. These findings strikingly correspond to several other findings (BUWAL, 1999; Dobré et al., 2006; Hertig, 1979; Kumar and Kant, 2007; Lin et al., 2008; Rametsteiner et al., 2009; Šišák, 2011), and the overall pattern of perceived importance of forest functions can be described as prioritizing ecological and protective functions over social functions, which are in turn prioritized over use-related functions. Interestingly, the most valued functions were also those topics that residents wished to have more information about. Thus there is considerable potential for forest ecologists to provide more or better information. The current forest policy in Switzerland has a focus on making better use of the full capacity for wood production, conserving the forest area and maintaining the forest's protective and regulating functions, while simultaneously finding ways for conservation-oriented recreational use. These comparative results about residents' evaluation of forest functions suggest high acceptance of measures related to the latter functions, while wood production seems to be a topic that is still associated with forest exploitation and destruction. The demand for local or national wood products could be fostered more, and public education to counter false perceptions could play a part in promotion strategies.

With regard to preferences for forest qualities, related to research question (c), mixed forests and multisensory experiences were the most valued qualities. Residents reported valuing forests highly for visual pleasure, but also for other senses such as hearing and smell. They preferred light, clear 
Table 6. Preferences for forest infrastructure, grouped into factors according to principal component analysis (PCA, varimax rotation).

\begin{tabular}{|c|c|c|c|}
\hline Infrastructure elements in forests & Appealing $^{\mathrm{a}}$ & Annoying ${ }^{\mathrm{a}}$ & PCA factor loadings \\
\hline \multicolumn{4}{|l|}{ Factor 1: sports infrastructure } \\
\hline Vita parcours, running trails & $58 \%$ & $28 \%$ & 0.72 \\
\hline Mountain bike trails & $32 \%$ & $56 \%$ & 0.83 \\
\hline Horse riding paths & $48 \%$ & $34 \%$ & 0.64 \\
\hline Rope tree climbing parks & $37 \%$ & $45 \%$ & 0.71 \\
\hline \multicolumn{4}{|c|}{ Factor 2: infrastructure for social experiences } \\
\hline Nature education trails & $89 \%$ & $4 \%$ & 0.73 \\
\hline Fire sites & $78 \%$ & $13 \%$ & 0.73 \\
\hline Play areas & $61 \%$ & $25 \%$ & 0.57 \\
\hline Huts and shelters & $79 \%$ & $10 \%$ & 0.69 \\
\hline \multicolumn{4}{|l|}{ Not contributing to any factor } \\
\hline Many benches & $68 \%$ & $19 \%$ & $<0.50^{\mathrm{b}}$ \\
\hline Car park at forest edge & $66 \%$ & $22 \%$ & $<0.50^{\mathrm{b}}$ \\
\hline Many forest roads and paths & $54 \%$ & $35 \%$ & $<0.50^{\mathrm{b}}$ \\
\hline
\end{tabular}

forests with water bodies, whereas dark and dense forest parts seemed to be unattractive for a considerable portion of the sample. Since this was particularly evident with women, who are more aware of safety issues, it might be concluded that dark forests may be perceived as a threat to a feeling of safety in the forest. Overall, people had an ambivalent relationship towards wilderness: when asked about pristine forests in general, they approved of it, similar to earlier findings (e.g. Kleinhückelkotten et al., 2009). However, certain specific aspects of wilderness, such as deadwood, were perceived negatively (see Dobré et al., 2006; Nielsen et al., 2012). Broadleaf trees were slightly preferred to conifers, but mixed forests represented the ideal forest type for a large majority and were clearly preferred to monoculture forests. Such preferences for varied forest structures have been observed before (Gobster, 1992; Hull et al., 2000). Some incongruencies of participants' general associations with forests, which may shape the image they have of the forest, and the evaluation of forest functions should also be taken into consideration. For example, people valued aesthetic and regulating functions, but they were not prominent in their view of the forest, whereas productive functions were often associated with the forest, but valued lowest. This mismatch must be considered in management issues that relate to acceptance by residents.

Swiss residents did not generally like sports and fun infrastructure in the forest, but sport activities are important for specific subgroups and conflicts from multiple uses of forests seemed to remain a problem (Hunziker et al., 2012). In contrast, information and infrastructure for contemplative or educational activities (benches, trails) and social activi- ties (playgrounds, fire sites for barbecue) were largely appreciated. Of course, forests need to be accessible; therefore car park and roads were appreciated, although probably not highly liked (see Abildtrup et al., 2013). The preference for nature and light, mixed forest corresponded with the abstract qualities of forests. People appreciated forests with general landscape qualities that both stimulate and evoke a sense of safety. All of these aspects proved to be highly important. However, it will remain a challenge to manage the increasing pressure on the forest for leisure activities and, in particular, the diverse demands that cause conflict between different groups within the population.

With regard to the overall topic of this theme issue about the meaning and value of forest, it can be summarized that Swiss people had an active and positive relationship with the forest. They were interested in it, they cared about it and they valued its diversity and its natural elements for their own sake. They loved to visit the forest and experience it with all their senses. For information and communication practice, some knowledge gaps and unfulfilled needs have been detected which should be addressed in future. For example, the respondents wished to know more about forests and valued educational infrastructure in forests. Also, many residents still seemed to be influenced by discussions from decades ago about "forest dieback" or by international reports, and they perceived Swiss forest health too negatively. The Swiss Socio-cultural Forest Monitoring WaMos intends to further observe these perceptions and use the results for a future-oriented and user-oriented management of Swiss forests. Based on the similarity to findings of other studies, there is much reason to assume that findings can be general- 
ized for many countries in Central Europe with similar types of forest. However, there may also be regional differences, and this study therefore serves as a baseline to gain regional comparative evidence, for example with regard to other European countries, for international research about forest perceptions.

Data availability. The underlying research data can be obtained from the authors. The data are not yet publicly accessible, because further analyses are currently being conducted in a follow-up project.

Author contributions. JF, NB and EvL contributed equally to the preparation, field work and analysis of the overall survey. MH was project leader and responsible for grant writing, overall concept and communication. JF prepared the manuscript with contributions from all co-authors.

Competing interests. The authors declare that they have no conflict of interest.

Acknowledgements. This research was funded by the Swiss Federal Office of Environment and the Swiss Federal Research Institute WSL. We thank two anonymous reviewers for their very helpful comments.

Edited by: Benedikt Korf

Reviewed by: two anonymous referees

\section{References}

Abildtrup, J., Garcia, S., Olsen, S. B., Stenger, A.: Spatial preference heterogeneity in forest recreation, Ecol. Econ., 92, 67-77, https://doi.org/10.1016/j.ecolecon.2013.01.001, 2013.

Backhaus, N., Buser, C., Butticaz, M., Jorio, D., and Speich, M.: Wirtschaftliche Auswirkungen des Sommertourismus im UNESCO Biosphärenreservat Val Müstair Parc Naziunal, Human Geography Series 27, Zurich, Institute of Geography of University of Zürich, 2013.

Bauer, N., Wallner, A., and Hunziker, M.: The change of European landscapes: Human-nature relationships, public attitudes towards rewilding, and the implications for landscape management, J. Environ. Manage., 90, 2910-2920, https://doi.org/10.1016/j.jenvman.2008.01.021, 2009.

Broggi, M. F.: Waldsterben - Was ist daraus geworden?, GAIA: Ecological Perspectives for Science and Society, 11, 10-11, 2002.

BUWAL: Gesellschaftliche Ansprüche an den Schweizer Wald Meinungsumfrage, Bern, BUWAL, 1999.

Côte, M., Wartmann, F., and Purves, R.: The trouble with forest: definitions, boundaries and values, Geogr. Helv., in review, 2018.

Dobré, M., Lewis, N., and Granet, A.-M.: Comment les français voient la forêt et sa gestion, RDV tech., 11, 55-63, 2006.
Gehring, K.: Landscape Needs and Notions. Preferences, expectations, leisure motivation, and the concept of landscape from a cross-cultural perspective, Birmensdorf, Swiss Federal Research Institute WSL, 2006.

Gobster, P.: Forest Aesthetics, Biodiversity, and the Perceived Appropriateness of Ecosystem Management Practices, in: Defining Social Acceptability in Ecosystem Management, A Workshop Proceedings, 23-25 June 1992.

Hertig, H. P.: Die Einstellung der Bevölkerung zu Problemen des Waldes und der Waldwirtschaft: Ergebnisse einer Meinungsumfrage, Bern, Schweizerische Gesellschaft für Praktische Sozialforschung/Forschungszentrum für schweizerische Politik, Universität Bern, 1979.

Hull, R. B., Robertson, D. P., Gregory, J., Buhyof, G. J., and Kendra, A.: What are we hiding behind the visual buffer strips? Forest aesthetics reconsidered, J. Forest, 98, 34-38, 2000.

Hunziker, M., Felber, P., Gehring, K., Buchecker, M., Bauer, N., and Kienast, F.: Evaluation of landscape change by different social groups. Results of two empirical studies in Switzerland, Mt. Res. Dev., 28, 140-147, https://doi.org/10.1659/mrd.0952, 2008.

Hunziker, M.: Einstellungen der Bevölkerung zu möglichen Landschaftsentwicklungen in den Alpen, Birmensdorf, Eidg. Forschungsanstalt WSL, 2000.

Hunziker, M., von Lindern, E., Bauer, N., and Frick, J.: Das Verhältnis der Schweizer Bevölkerung zum Wald, Birmensdorf, Eidg. Forschungsanstalt WSL, 2012.

Kaplan, R. and Kaplan, S.: The Experience of Nature: A Psychological Perspective, New York, Cambridge University Press, 1989.

Kleinhückelkotten, S., Neitzke, H.-P., and Wippermann, C.: Einstellungen den Deutschen zu Wald und Forstwirtschaft, Forst Holz, 64, 12-19, 2009.

Kumar, S. and Kant, S.: Exploded logit modeling of stakeholders' preferences for multiple forest values, Forest Policy Econ., 9, 516-526, https://doi.org/10.1016/j.forpol.2006.03.001, 2007.

Lin, J.-C., Wang, P.-J., Chen, L.-C., and Lin, Y. J.: An analysis of forest ecosystem services cognition by people with different environmental attitudes, Taiwan J. For. Sci., 23, 51-62, 2008.

MCPFE Ministerial Conference on the Protection of Forests in Europe: State of Europe's forests 2003, The MCPFE report on sustainable forest management in Europe, Vienna, MCPFE, 2003.

Müller, M., Mayer, M., and Job, H.: Totholz und Borkenkäfer im Nationalpark Bayerischer Wald aus touristischer Perspektive, in: Die Destination Nationalpark Bayerischer Wald als regionaler Wirtschaftsfaktor, edited by: Huber, J., Verlag Nationalpark Bayerischer Wald, 100-116, 2008.

Nielsen, A. B., Heyman, E., and Richnau, G.: Liked, disliked and unseen forest attributes: relation to modes of viewing and cognitive constructs, J. Environ. Manage., 113, 456-466, https://doi.org/10.1016/j.jenvman.2012.10.014, 2012.

Pauli, B.: Wald und Forstwirtschaft im Meinungsbild der Gesellschaft, Mitt. Staatsforstverwalt. Bayerns, 50, 1-228, 2000.

Purcell, A. T.: Abstract and specific attributes and the experience of landscape, J. Environ. Manage. 34, 159-177, https://doi.org/10.1016/S0301-4797(05)80149-5, 1992.

Rametsteiner, E., Eichler, L., and Berg, J.: Shaping forest communication in the European Union: public perceptions of forests and forestry, Final Report, available at: http://ec.europa.eu/ agriculture/fore/publi/public-perception/report_en.pdf (last access: 7 November 2018), 2009. 
Schenk, A., Hunziker, M., and Kienast, F.: Factors influencing the acceptance of nature conversation measures - a qualitative study in Switzerland, J. Environ. Manage., 83, 66-79, https://doi.org/10.1016/j.jenvman.2006.01.010, 2007.

Šišák, L.: Forest visitors' opinions on the importance of forest operations, forest functions and sources of their financing, Journal of Forest Science, 57, 266-270, 2011.
Stelzig, I.: Zur Akzeptanz von Totholz in deutschen WaldNationalparken, in: Naturbildung und Naturakzeptanz, edited by: Trommer, G. and Stelzig, I., Beiträge zur biologischen Forschung, Frankfurt, Shaker-Verlag, 117-123, 2000.

Wild-Eck, S., Schenk Zumbrunn, A., and Hunziker, M.: Naturereignisse im Spiegel der Gesellschaft, Birmensdorf, Eidg. Forschungsanstalt WSL, 2004. 